[0212-7199 (2008) 25: 4; pp 183-186] ANALES DE MEDICINA INTERNA Copyright (C) 2008 ARAN EDICIONES, S.L.

AN. MED. INTERNA (Madrid) Vol. 25, N. ${ }^{\circ} 4$, pp. 183-186, 2008

\title{
Una causa infrecuente de tromboembolismo pulmonar
}

\author{
J. N. SANCHO-CHUST, E. CHINER-VIVES, A. LUZ ANDREU-RODRÍGUEZ, \\ M. LLOMBART-CANTÓ, C. SENENT-ESPAÑOL, G. MEDIERO-CARRASCO \\ Sección de Pneumología. Hospital Universitari Sant Joan. Alicante
}

AN INFREQUENT CAUSE OF PULMONARY THROMBOEMBOLISM

\section{RESUMEN}

Presentamos un caso de tromboembolismo pulmonar en paciente joven desencadenada por un viaje de larga duración, en el que se demostró una mutación homocigota en el gen de la metilentetrahidrofolato reductasa. Esta mutación puede provocar una hiperhomocisteinemia, que es un factor de riesgo conocido para enfermedad tromboembólica venosa (ETV). En el manejo de estos pacientes se deben descender los niveles de homocisteína, así como realizar profilaxis tromboembólica ante situaciones de riesgo transitorias. Es importante conocer cuándo debe ser realizado su screening, ya que se encuentran detrás de un importante número de casos de ETV.

PALABRAS CLAVE: Trombofília hereditaria. Metilentetrahidrofolato reductasa. Hiperhomocisteinemia. Enfermedad tromboembólica venosa. Tromboembolismo pulmonar. Síndrome de la clase turista.

\begin{abstract}
We present a case of pulmonary thromboembolism in a young patient triggered by a long haul travel, in which a homocygotic mutation in the gene of the metilentetrahidrofolate reductase was demonstrated. This mutation can cause hyperhomocysteinemia that is a recognized risk factor for venous thromboembolism (VTE). In the management of these patients, the levels of homocysteine should be lowered, as well as use of thromboprophylaxis before transitory risk situations. It is important to know when the screening should be performed, because they are behind an important number of cases of VTE.
\end{abstract}

KEY WORDS: Inherited thrombophilia. Methylenetetrahydrofolate reductase. Hyperhomocysteinemia. Venous thromboembolism. Pulmonary thromboembolism. Economy class syndrome.

Sancho-Chust JN, Chiner-Vives E, Andreu-Rodríguez AL, Llombart-Cantó M, Senent-Español C, Mediero-Carrasco G. Una causa infrecuente de tromboembolismo pulmonar. An Med Interna (Madrid) 2008; 25: 183-186.

\section{INTRODUCCIÓN}

El tromboembolismo pulmonar (TEP), complicación de la trombosis venosa profunda (TVP), constituye la expresión de una misma entidad: la enfermedad tromboembólica venosa (ETV) (1). Estudios realizados en Europa y EE.UU. muestran una incidencia anual de TVP de 160 casos/100.000/año, 20 casos/100.000/año para TEP sintomáticos no fatales y 50 casos/100.000/año para TEP fatales detectados en autopsias. Los factores de riesgo más relevantes en la práctica clínica son la cirugía, el traumatismo, la inmovilización y las neoplasias (2).

Presentamos el caso de un paciente joven afecto de TEP, en el que se demostró la existencia de trombofília y, como factor desencadenante, un viaje transcontinental en avión. Tal caso sirve para reseñar la importancia de efectuar un estudio etiológico en determinados pacientes, debido a las potenciales consecuencias clínicas en su prevención.

\section{CASO APORTADO}

Varón de 34 años, fumador de 10 paquetes/año, sin otros factores de riesgo cardiovascular. De profesión comercial, residente en China en medio urbano. Ingresó en nuestra Sección por dolor en hemitórax izquierdo de características pleuríticas de mes y medio de evolución. El inicio del cuadro coincidió con un viaje en avión de vuelta a España, tras el cual presentó dolor en pantorrilla izquierda, tumefacción e impotencia funcional. Posteriormente presentaba dolor torácico pleurítico con empeoramiento progresivo. No refería disnea, síncope, tos ni hemoptisis.

A la exploración física presentaba buen estado general, hidratación y coloración. Estaba normotenso y afebril, con una frecuencia cardíaca de $78 \mathrm{lpm}$ y una frecuencia respiratoria de $16 \mathrm{rpm}$. La auscultación cardíaca era rítmica y sin soplos, y a la pulmonar presentaba murmullo vesicular disminuido y abolición de las vibraciones vocales en tercio inferior de hemitórax izquierdo. En miembros inferiores no presentaba edemas ni signos de trombosis venosa profunda, siendo el resto de la exploración normal. 
La radiografía de tórax reveló una imagen de derrame pleural en tercio inferior de hemitórax izquierdo, que borraba el hemidiafragma ipsilateral, con presencia de atelectasias laminares (Fig. 1). La gasometría arterial $\left(\mathrm{FIO}_{2} 0,21\right)$ mostró pH 7,41, $\mathrm{PCO}_{2} 36,3$ mmHg, $\mathrm{PO}_{2}$ $86,7 \mathrm{mmHg}$ y $\mathrm{HCO}_{3} 22,5 \mathrm{~mm} / 1$. En el ECG existía ritmo sinusal a 70 lpm, con intervalo PR, eje QRS e intervalo QT normales, QRS estrecho y ausencia de alteraciones en la repolarización. La analítica sanguínea no reveló hallazgos de mención, salvo un dímero D por el método ELISA de 537 ng/ml. La Gammagrafía de ventilación-perfusión halló alteraciones en segmentos posteriores y basales de pulmón izquierdo secundarios a derrame pleural, sin defectos de perfusión con ventilación conservada sugestivos de TEP, determinándose un patrón de baja probabilidad para TEP agudo. Se realizó una toracocentesis diagnóstica, extrayéndose $20 \mathrm{~cm}^{3}$ de líquido sero-hemático con el siguiente patrón bioquímico: 68.000 hematíes $/ \mathrm{mm}^{3}, 6.170$ leucocitos $/ \mathrm{mm}^{3}$ (41\% PMN, 59\% linfocitos), glucosa $71 \mathrm{mg} / \mathrm{dl}, \mathrm{LDH}$ $182 \mathrm{~mm} / \mathrm{l}$, proteínas 3,65 , colesterol $47 \mathrm{mg} / \mathrm{dl}$, ADA $33 \mathrm{UI} / \mathrm{l}$. Tanto el Zhiel, el Lowenstein, como los cultivos del líquido pleural fueron negativos. La citología del líquido mostró ausencia de malignidad. Se realizó con posterioridad un Angio-TAC torácico, que reveló una imagen sugestiva de pequeño trombo en arteria lobar inferior izquierda, a nivel de la bifurcación segmentaria, además de moderada cantidad de derrame pleural izquierdo asociado a atelectasia por compresión, sin observarse signos de trombosis venosa profunda (Fig. 2). Las pruebas funcionales respiratorias mostraron los siguientes resultados: FVC $5410 \mathrm{ml}$ (91\%), FEV1 $4070 \mathrm{ml}$ (88\%), FEV1/FVC 75\% (96\%), con test broncodilatador negativo.

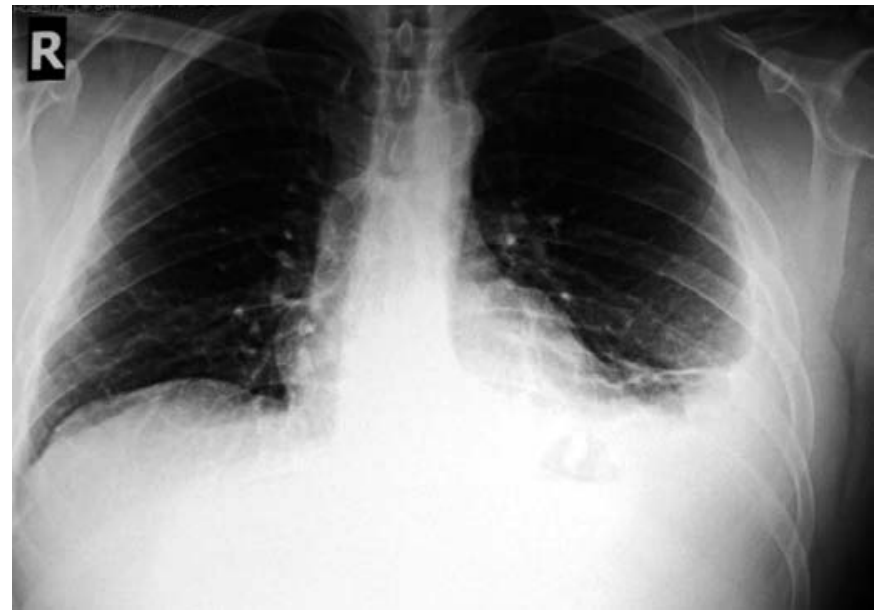

Fig. 1. Radiografía lateral y antero-posterior de tórax, en las que se aprecia imagen de derrame pleural en tercio inferior de hemitórax izquierdoque borra hemidiafragma ipsilateral y atelectasias laminares con localización en lóbulo inferior izquierdo.

Se estableció el diagnóstico de Tromboembolismo pulmonar en fase subaguda y Síndrome de la clase turista, por lo que se instauró tratamiento anticoagulante con acenocumarol.

Debido a la presencia de TEP en paciente joven sin aparentes factores de riesgo, tres meses más tarde se procedió a realizar estudio de hipercoagulabilidad en el que se detectó una mutación homocigota C677T para el gen de la Metilentetrahidrofolato Reductasa. Se determinaron niveles plasmáticos de homocisteína ( $54 \mu \mathrm{mol} / \mathrm{l})$, ácido fólico $(2 \mathrm{ng} / \mathrm{dl})$ y cianocobalamina ( $3 \mathrm{ng} / \mathrm{dl})$. Ante estos hallazgos, se decidió mantener el tratamiento anticoagulante durante 6 meses e iniciar terapia con ácido fólico y cianocobalamina. En controles clínicos posteriores, el paciente permanecía asintomático, con pinzamiento residual de seno costo-frénico izquierdo en la Rx tórax y resolución prácticamente completa de los defectos de ventilaciónperfusión en la gammagrafía de control.

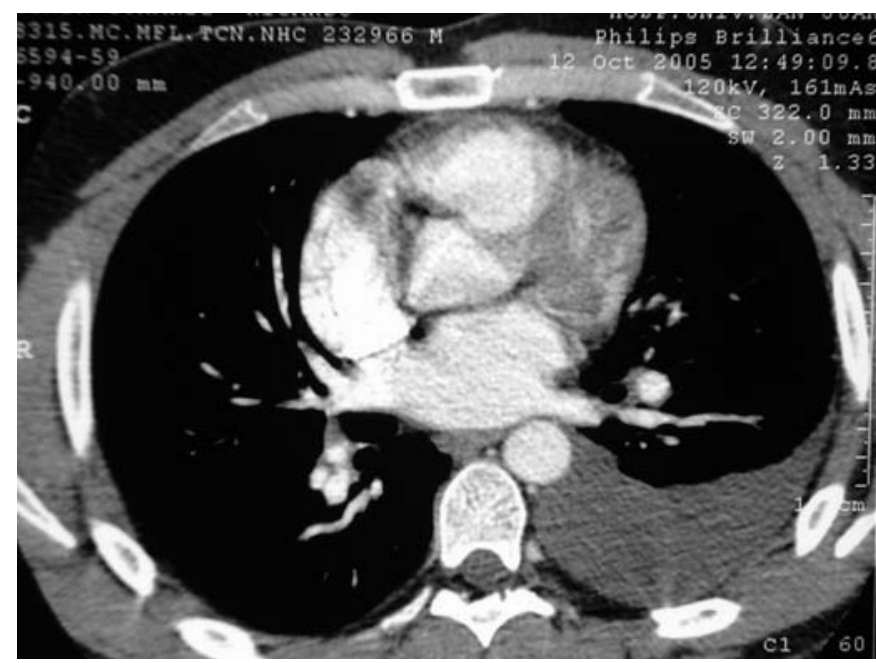

Fig. 2. Dos imágenes del angio-TAC torácico con moderada cantidad de derrame pleural izquierdo asociado a atelectasia en lóbulo inferior izquierdo. Se objetiva imagen de baja atenuación sugestiva de pequeño trombo en arteria lobar inferior izquierda a nivel de la bifurcación segmentaria.

\section{TABLA I}

CAUSAS HEREDITARIAS DE TROMBOFILIAS, DIVIDIDAS POR GRUPOS ETIOPATOGÉNICOS. SE INDICA LA PREVALENCIA EN LA POBLACIÓN GENERAL Y EN PACIENTES CON ETV, ASÍ COMO EL RR DE DESARROLLAR ETV AL QUE SE ASOCIAN

\begin{tabular}{llccc}
\hline & & $\begin{array}{c}\text { Prevalencia } \\
\text { Población }\end{array}$ & Pacientes & $R R$ \\
\hline Presencia & Factor V Leiden & $3-15$ & 20 & 5 \\
factores & Protrombina C20210A & $1-2$ & $4-7$ & $2-3$ \\
anormales & Hiperhomocisteinemia & 5 & 10 & 2,5 \\
Elevación factores & Elevación Factor VIII & 11 & 25 & 5 \\
procoagulantes & & & & \\
Déficit factores & Déficit Antitrombina & $0,07-016$ & $1-3$ & 20 \\
anticoagulantes & Déficit Proteína C & $0,2-0,4$ & $3-5$ & 10 \\
& Déficit Proteína S & $0,03-0,13$ & 1,5 & 10 \\
\hline
\end{tabular}

\section{DISCUSIÓN}

Trombofília hace referencia al término usado actualmente para describir la elevada predisposición a fenómenos tromboembólicos venosos debido a causas hematológicas, ya sean hereditarias o adquiridas (3). Las causas hereditarias han ganado protagonismo en los últimos años debido a los avances en el campo de la genética. Podemos dividirlas en varios grupos etiopatogénicos (Tabla I) (4).

Desde que se describió el "síndrome de la clase turista" (5), se ha considerado los viajes en avión como un factor de riesgo para ETV debido a la inmovilización prolongada, especialmente si son de larga duración (6). Este factor, además de la trombofilia, fue el responsable de la ETV en nuestro paciente, que presentó TEP siendo joven y aparentemente sano.

Las indicaciones para realizar un estudio de trombofilias hereditarias son (2): 
- Todos los pacientes con un primer episodio espontáneo de ETV, a) Menores de 50 años con ETV y un desencadenante transitorio; b) Pacientes con ETV y anticonceptivos orales o embarazo como único factor de riesgo; c) ETV recurrente; d) Tromboflebitis superficiales de repetición en ausencia de cáncer o insuficiencia venosa; e) Menores de 50 años con ETV en localizaciones inusuales; f) Pacientes con necrosis dérmica inducida por warfarina o neonatos con purpura fulminans no relacionada con sepsis; g) Familiares de primer grado de pacientes con trombofilia sintomática; h) Dos abortos consecutivos, tres no consecutivos o una muerte fetal de más de 20 semanas; i) Preeclampsia severa; y j) Niños con ETV.

En nuestro caso se realizó estudio de trombofilia ya que se trataba de un paciente menor de 50 años con una ETV y un desencadenante transitorio (vuelo China-España). Actualmente se recomienda incluir en el estudio: recuento celular sanguíneo coagulación, resistencia a la Proteína C Activada/Factor V, Protrombina, Homocisteína, MTHFR, Antitrombina, Proteína C, Proteína S, Ac antifosfolípido y anticardiolipina. Un tema de controversia es cuándo se debe realizar el estudio, ya que la fase aguda y la toma de anticoagulantes orales (ACO) pueden alterar los resultados. Las recomendaciones van encaminadas a realizarlo al finalizar la anticoagulación, o bien durante ésta, sustituyendo temporalmente los ACO por HBPM (1). Nosotros la realizamos a los tres meses, utilizando durante las tres semanas previas HBPM, ya que pensamos nos podía ser útil de cara a posibles cambios en la actitud terapéutica.

La Metilentetrahidrofolato Reductasa (MTHFR) es una enzima que convierte el folato en metilentetrahidrofolato, un cofactor necesario para la degradación de la homocisteína. Existe una mutación, llamada C677T, en la que se sustituye citosina por timina en el nucleótido 677 , dando como resultado final una enzima termolábil a $37^{\circ} \mathrm{C}$. Su prevalencia en la raza caucasiana es del $34-37 \%$ para heterocigotos y $10-12 \%$ para homocigotos. Está descrita otra mutación, A1298C, cuya prevalencia es menor (9-20\%) (4). Las mutaciones en el gen de la MTHFR parecen relacionarse con una elevación moderada en el riesgo de Preeclampsia y Abruptio Placentae, pero se necesitan más estudios para su confirmación (7). Su relación con la Enfermedad Inflamatoria Intestinal es dudosa, a la vista de resultados contradictorios (8). Se ha asociado a recién nacidos con defectos en el tubo neural, encontrando hiperhomocisteinemia en el $20 \%$ de sus madres (9). También se ha comprobado elevación de sus niveles en pacientes con Síndrome de Apneas-Hipopneas del Sueño (SAHS), en probable relación con las alteraciones cardiovasculares que esta entidad provoca (10).

En sujetos homocigotos C677T la actividad enzimática se reduce en más de un 50\%. Pese a ello, estos pacientes sólo desarrollarán hiperhomocisteinemia si coexisten unos niveles bajos de ácido fólico y cianocobalamina en plasma (11). La homocisteína es producida como consecuencia de la degradación del aminoácido metionina. Niveles por encima de 15 $\mu \mathrm{mol} / \mathrm{l}$ pueden considerarse significativamente elevados, pudiendo reducirse administrando ácido fólico y cianocobalamina (7). Se ha visto que la hiperhomocisteinemia tiene una prevalencia del $5 \%$ en la población general (2). Entre sus causas cabe citar el déficit de ácido fólico o cianocobalamina, insuficiencia renal, hipotiroidismo, lupus eritematoso sistémico y mutación en la MTHFR.

Si el efecto que produce esta mutación es la hiperhomocisteinemia, cabe preguntarse acerca de sus consecuencias. En pacientes con ETV la hiperhomocistinemia tiene una prevalencia del 10\%, con un RR de 2,5 (2). Estos datos llevaron a pensar que quizá la homocisteína actuara como factor etiopatogénico, pero estudios recientes contradicen esta hipótesis, argumentando que la normalización de sus niveles no condiciona un descenso en el riesgo de desarrollar ETV. Por ello, actualmente surge la idea de que no se trata de la causa, sino más bien de una consecuencia del daño producido en los vasos sanguíneos por otros mecanismos. Basándose en esto, hay autores que desaconsejan tratar la hiperhomocisteinemia (11), pero otros argumentan que es posible que la hiperhomocisteinemia contribuya (aunque sea en menor cuantía de lo que se pensaba) al riesgo de trombosis, recomendando su tratamiento $(4,7)$.

Un estudio reciente (11) analiza la posible asociación entre la mutación homocigota C677T y el riesgo de ETV sobre un gran número de pacientes, hallando una odds ratio de 0,94 (IC 0,81-1,08), concluyendo que no existe asociación causal, aunque la recogida de factores de riesgo mediante cuestionarios autocumplimentados y la ausencia de estudios genéticos podría limitar tal afirmación.

Nuestro paciente presentaba una homocisteína por encima del punto de corte asociado a ETV (> $18 \mu \mathrm{mol} / \mathrm{l})(11)$, posiblemente desencadenada por un déficit dietético. Por ello, se decidió comenzar terapia con ácido fólico y cianocobalamina, teniendo en cuenta que este tratamiento es relativamente seguro y barato $(2,91 € /$ mes $(7))$, ya que nos pareció una buena opción a la espera de nuevas evidencias científicas que determinen el beneficio del descenso de la hiperhomocisteinemia en pacientes con mutación homocigota de la MTHFR. Hay estudios que defienden la determinación de la homocisteína de forma periódica en el seguimiento de estos pacientes (7). De esta forma se pretende evaluar la eficacia de la terapia vitamínica. En este caso, se realizaron determinaciones a los 3 y 6 meses, encontrando una normalización de sus niveles (11 y $9 \mu \mathrm{mol} / 1$ respectivamente).

Otro tema con cierta controversia es la duración de la profilaxis secundaria en las trombofilias. Hay estudios en los que la trombofilia no parece predecir el riego de recidiva durante los 2 años siguientes a la retirada del tratamiento anticoagulante. Pero el escaso número de pacientes en estos estudios ha impedido realizar recomendaciones contundentes. En general, se acepta que los déficit de antitrombina, proteína $C$, proteína $\mathrm{S}$, factor $\mathrm{V}$ Leiden o mutaciones combinadas son de alto riesgo, recomendándose individualizar la duración del tratamiento, que puede llegar a ser indefinido (1). En el caso de pacientes homocigotos $\mathrm{C} 677 \mathrm{~T}$, se recomienda realizar un tratamiento anticoagulante indefinido si coexisten más mutaciones en otros factores de la coagulación. En caso contrario, la duración del tratamiento será la convencional, realizándose profilaxis en situaciones de riesgo. Nuestro paciente no presentaba un defecto combinado, por lo que se decidió realizar la profilaxis secundaria durante 6 meses y suspender posteriormente la anticoagulación, recomendando profilaxis primaria para posteriores vuelos de larga duración. 


\section{Bibliografía}

1. Uresandi F, Blanquer J, Conget F, et al. Guía para el diagnóstico, tratamiento y seguimiento de la tromboembolia pulmonar. Arch Bronconeumol 2004; 40: 580-94.

2. Nicolaides AN, Breddin HK, Carpentier P, et al. Thombophilia and venous thromboembolism. International Consensus Statement. Int Angiol 2005; 24: 1-26.

3. Rosendaal FR. Venous thrombosis: a multicausal disease. Lancet 1999; 353: 1167-73.

4. Moll S. Thrombophilias-Practical Implications and Testing Caveats. J Thromb Thrombolysis 2006; 21: 7-15.

5. Cruickshank JM, Gorlin R, Jennet B. Air travel and thrombotic episodes: the economy class syndrome. Lancet 1988; 2: 497-8.

6. Lapostolle F, Surget V, Borron SW, Desmaizières M, Sordelet D, Lapandry C, et al. Severe pulmonary embolism associated with air travel. N Engl J Med 2001; 345: 828-9.
7. Varga EA, Sturm AC, Misita CP, et al. Homocysteine and MTHFR Mutations: relation to thrombosis and coronary artery disease. Circulation 2005; 111: 289-93.

8. Fernández-Miranda C, Martínez M, Casis C, et al. Hiperhomocisteinemia y mutaciones de la Metilentetrahidrofolato Reductasa $677 \mathrm{C} \rightarrow \mathrm{T}$ y 1298A $\rightarrow \mathrm{C}$ en pacientes con enfermedad inflamatoria intestinal. Rev Esp Enferm Dig 2005; 97: 497-504.

9. Botto LD, Yang Q. 5,10-Methylenetetrahydrofolate reductase gene variants and congenital anomalies: A HuGE review. Am J Epidemiol 2000; 151: 862-77

10. Can M, Açikgöz S, Mungan G, et al. Serum Cardiovascular Risk Factors in Obstructive Sleep Apnea; Chest 2006; 129: 233-7.

11. Bezemer ID, Doggen CJ, Vos HL, et al. No Association Between the Common MTHFR 677C $\rightarrow$ T Polymorphism and Venous Thrombosis Results From the MEGA Study. Arch Intern Med 2007; 167: 497-501. 